\title{
Taxation and Evasion in the Presence of Extortion by Organized Crime
}

By: Michael Alexeev, Eckhard Janeba and Stefan Osborne

Working Paper Number 256

November 1999 
PLEASE DO NOT CITE

COMMENTS WELCOME

\title{
Taxation and Evasion in the Presence of Extortion by Organized Crime $^{\mathrm{H}}$
}

\author{
by \\ Michael Alexeev* \\ Eckhard Janeba** \\ and \\ Stefan Osborne***
}

Revised in November 1999

\begin{abstract}
We model the taxation behavior of a revenue maximizing government in the presence of tax evasion by firms and the existence of a competing tax collector, in this case organized crime (or the "mafia"). In order to evade taxes, the firm must shift some of its sales underground, incurring convex costs. We show that the government's optimal tax rate and revenue in equilibrium are higher when the mafia is present. Furthermore, we assume that the mafia has limited ability to tax the firm's share of above ground activities. Our analysis shows that under certain assumptions, an increase in this ability does not affect the government's tax rate and revenue.
\end{abstract}

Journal of Economic Literature Classification Codes: H26, H21, and P51

Keywords: Optimal taxation, tax evasion, organized crime

* Department of Economics, Indiana University, Bloomington

** University of Colorado at Boulder and NBER

*** U.S. Department of Agriculture, Washington, DC

For correspondence please contact Michael Alexeev at Department of Economics, Wylie Hall, Indiana University, Bloomington, IN 47405; e-mail: malexeev@indiana.edu; fax: (812) 855-3736.

\footnotetext{
${ }^{\mathrm{H}}$ We are grateful to Jim Leitzel, David Schmidt, Dan Berkowitz, Joel Slemrod and the workshop participants at Indiana University, University of Pittsburgh, and University of Michigan for insightful comments and discussion. All remaining errors and omissions are our own responsibility. Michael Alexeev's work on this paper was partially supported by the William Davidson Institute at the University of Michigan School of Business Administration.
} 


\section{Taxation and Evasion in the Presence of Extortion by Organized Crime}

\section{Introduction}

In countries where the state is relatively weak, alternative institutions may develop that usurp or supplement some important state functions. In particular, organized crime groups, which we will call the mafia, may be able to extort payments from firms, perhaps in return for providing protection from other criminals and a measure of property rights enforcement (see for example, Schelling (1984a,b) and Gambetta (1993) for particularly cogent description and analysis). While the relationship between firms and the mafia is usually quite complex, the payments that firms make can be viewed as a form of additional taxation of firms.

The presence of taxation by a mafia will affect the outcome of government tax policy. This paper examines the optimal tax policy of the state in an environment where the mafia competes with the state for extracting payments from firms. The paper's model is particularly relevant to some of the economies in transition-- most notably, Russia--as well as to more traditional mafia strongholds such as Southern Italy.

Following Grossman (1995) and the appropriate references therein, we assume that the main motivation of both the state and mafia is to extract the maximum possible rents from firms. In our model, a representative firm faces a sales tax imposed by the state and a sales tax imposed by the mafia. The firm can evade the state tax by shifting 
part of its activities underground. ${ }^{1}$ We assume that while the firm's costs of above ground sales are zero, underground operations impose additional costs on the firm. For example, these could be the costs of operating in secret, including the cost of reaching customers in the absence of open advertising. Unlike the state, the mafia can tax both underground and above ground sales, but generally, the mafia finds it more difficult to tax the above ground transactions.

The assumption that the mafia can tax illegal activity more easily is motivated by a widely accepted observation that the organized crime extracts rent primarily from illegal businesses:

...why is the biggest victim of organized crime an illegal business rather than some legal business? ... A first criterion for target selection by organized extortionists is that the victims should be poor at protecting themselves. In particular, one would like victims who have no ready access to the law. Criminals would therefore usually be ideal victims. (Schelling, 1984a, p. 186)

Schelling's argument refers to "ghosts" or firms that do not have any above ground operations. The same considerations, however, are applicable to firms that combine above and underground activities. The gist of Schelling's argument was that underground firms could not ask the state for protection against either organized or "disorganized" criminals. Therefore, underground firms had both greater need for the mafia's services (protection against other criminals) and less opportunity to resist extortion by the mafia itself. The same reasoning can be applied to the "mixed" firms. We argue that it is easier for the mafia to tax the firm's underground activities such as untaxed sales, than to tax above ground activities. The firm presumably cannot ask the state to enforce contracts

\footnotetext{
${ }^{1}$ This assumption can be relaxed by letting the state catch tax evaders with some probability, and then recover the tax due plus a fine. This extension does not produce qualitatively different results.
} 
over underground transactions or uphold property rights over underground inventory. It should be easier for the firm to appeal for state protection with respect to legitimate activities. In addition to being more likely (and able) to seek the protection of the state, it would be difficult for the firms to allocate cash generated by legal transactions to make payoffs to the mafia. The assumption of different tax rates imposed by the mafia on above and underground activities may be particularly easy to accept in the framework where the firm possesses a factor of production (e.g., labor) that it allocates between above ground and underground production. (Such a setup would be technically identical to ours if the production function is linear.) This type of framework is used by Grossman (1995) as well as Johnson et al. (1998) who assume that the mafia taxes only illegal activity. We believe, however, that there is no a priori reason to expect the mafia to restrict itself voluntarily in such a way. If the official government is relatively weak (for instance, in Russia) the mafia can and does tax legal as well as illegal sales, ${ }^{2}$ although presumably it is somewhat constrained in its ability to tax the former. We model this constraint as an exogenous limitation on the tax rate that the mafia can impose on above ground transactions.

The exogenous nature of the limit on the mafia's above ground tax rate can be justified by assuming that when firms appeal for protection from the government, they deal with a law-enforcement agency that operates largely independently from the revenue-maximizing tax authorities. While this law-enforcement agency may prosecute illegal economic activities or report them to the tax authorities, the latter cannot bargain

\footnotetext{
${ }^{2}$ Goldman, 1996. See also Reuter, 1983 for a discussion of organized crime's involvement in legal activity.
} 
with the firm over the level of protection from the mafia, making it contingent on the size of tax payments.

In our model, the presence of a mafia that taxes predominantly underground sales normally makes it more costly for firms to escape official taxation, thereby reducing tax evasion and increasing government revenue. As long as the mafia is not too "strong" and the demand is not too elastic, the government's optimal tax rate and revenue in equilibrium are higher when the mafia is present. This result is consistent with a widespread perception of an excessively high tax burden in Russia (which served as an inspiration for our model) and Ukraine -- countries notorious for the large role of organized crime in their economies. For example, according to a World Economic Forum (1997) survey, the tax burden in Russia and Ukraine ranked as one of the heaviest of all countries examined. Egorova and Petrov (1996) found that the tax burden on value added in Russia was larger than in 20 other countries, including developed nations and other economies in transition. Survey results reported by Zhuravskaia and Frye (1998) also indicate that Russian shopkeepers rate taxes as their greatest problem.

Furthermore, we show that in some circumstances, even as the mafia becomes "stronger" (appropriately defined), the government's optimal tax rate does not change and its revenue declines only to the extent that mafia taxation reduces overall sales. Combined with the first result, this suggests that revenue-maximizing governments, when faced with tax evasion by firms, may not be too eager to fight the mafia. Note, however, that when the mafia becomes sufficiently strong and is able to raise its tax rate on above ground transactions, competition between the government and mafia for above ground 
tax revenues becomes a zero-sum game. In this case, the government's incentives to combat the mafia may become stronger.

Our results are valid only to the extent that taxation represents a net cost to the producers. If the government or the mafia provide public goods that enhance the firm's output, the outcome may be different. In this regard, it is instructive to examine a model by Grossman (1995) that is closely related to ours, but arrives at strikingly different results.

Grossman's setup also has a government and a mafia who tax a representative firm. The government taxes only above ground output, while the mafia taxes only underground activity. But in his model production requires some public good, that can be supplied by either of these "rival kleptocrats." Grossman concentrates on the case where both the government and the mafia maximize their respective tax revenues net of the cost of their public good provision. So, both kleptocrats provide a net benefit to the firm (which could not produce at all in the absence of the government or mafia-supplied public good), rather than a cost, as in our model.

In Grossman's model, public goods supplied by the state could to some extent be used in underground production. But in the absence of a mafia, shifting production underground generates a negative externality. Specifically, decreased aboveground output reduces the government's tax base and therefore its supply of public goods, reducing the firm's productive potential. The presence of mafia taxation of underground production, coupled with mafia supply of public goods, eliminates the negative externality. In addition, the mafia breaks the state monopoly on the supply of public goods, reducing their cost to the firm in terms of taxes. As a result, in Grossman's model the firm always 
gains from the presence of a mafia, while in our model, the firm always loses from the mafia's presence. Thus our model is complementary to Grossman's in the sense that he stresses the net benefits provided to firms in the form of public goods supplied by the tax agencies, while we emphasize the costs of taxation. ${ }^{3}$ The applicability of either model depends on the balance of costs and benefits of taxation to the firms. It is also important to keep in mind that both models assume that the objective of the state is to maximize revenues, rather than enhance social welfare.

Our analysis shares some of the features with the literature on horizontal and vertical tax competition (see, for example, Keen and Kotsogiannis (1996) and Keen (1998)) but there are also important differences. Keen and Kotsogiannis (1996) whose paper is most relevant to our work, study tax competition in a model where capital is mobile across states within a federation. State governments compete via capital tax rates for investment to maximize their tax revenues (horizontal tax competition). In addition, capital is taxed by the federal government. Hence, each state and the federal government co-occupy a tax base (vertical competition). Keen and Kotsogiannis show that horizontal tax competition leads to tax rates being too low, that is, a simultaneous increase of all state tax rates would improve state revenues and often social welfare. By contrast, vertical tax competition leads to overtaxation in the sense that a reduction in the federal tax rate or state tax rate raises the sum of state and federal tax revenues.

Our model also has elements of both horizontal and vertical tax competition. Horizontally, the government and the mafia compete for the tax base because their relative tax values determine the distribution of the firm's sales between aboveground

\footnotetext{
${ }^{3}$ There are a number of other more or less technical differences between Grossman's model and ours, but they do not drive the main results.
} 
and underground. At the same time, there is an element of vertical competition because both the government and the mafia co-occupy the above ground tax base. Contrary to Keen and Kotsogiannis's result, however, all tax rates tend to be too low in our model. This divergence can be explained partly by the availability of an outside option. In our basic model, the firm's only outside option is not to produce at all. As a consequence, the optimal (combined) tax rate on above ground output is 100 percent. There is also a structural difference between the models. In order to have both types of competition, Keen and Kotsogiannis need to assume at least three taxing agents who extract rents (the federal and two state governments), whereas in our model there are only the government and the mafia.

Berkowitz and Li (1999) also study tax evasion in a framework with competing tax agencies levying a tax on the same base. Their interpretation also includes the mafia as one of the possible "competing taxers." Their main result relevant to our paper is that the combined tax rate increases as the number of tax agencies grows: Berkowitz and Li do not focus on comparisons of individual tax rates of separate tax agencies. Most important, in their model firms can evade all taxation on a portion of their output by escaping (partially) into the informal sector. Their model addresses only the horizontal aspect of tax competition among tax agencies.

Finally, Johnson, et al. (1997) analyze a model with a firm, a government, and a mafia. In their model, the firm makes a choice about shares of legal and illegal output, but the tax rates imposed by the state and the mafia in Johnson et al. are exogenous. They argue that neither the state nor the mafia can be modeled as optimizing players because they are not homogeneous groups and are affected by competing interests both from 
inside (different government levels) and outside (between mafia groups). While this may be largely true, particularly in the economies in transition, it is still reasonable to ask what would be the outcome of tax competition if the state and mafia optimized. Moreover, despite the fact that both government and mafia are complex organizations, the transaction costs of negotiation "inside" them are presumably relatively low and the degree of contract enforceability is relatively high, compared to the costs of negotiation and contract enforceability between each other. Therefore, at least at first blush, it makes sense to model them as unitary, rational actors.

The remainder of the paper is organized as follows. Section 2 describes the model and derives the main results of the paper under the assumption of inelastic demand. Section 3 extends the model to the case with downward sloping demand curves. Section 4 concludes.

\section{The Model}

Consider a game with three players, the firm, the state (or government) and the mafia. The firm can costlessly produce up to one unit of output that it sells at a price of one. The firm's above ground sales are taxed by the government at rate $t, 0 \leq t \leq 1$. The firm can evade the government's tax by selling its output at least partly underground. We denote the share of above ground sales by $\theta(0 \leq \theta \leq 1)$. The cost of selling $(1-\theta)$ units of output underground is denoted by $C(\theta)$. This cost function is assumed to be trice continuously differentiable with: 


$$
C(1)=0 ; C_{\theta} \leq 0 ; C_{\theta \theta}>0 ; C_{\theta \theta \theta} \geq 0 .{ }^{4}
$$

$C(\theta)$ represents both incidental costs of engaging in illegal behavior and perhaps the consequences of the government's law enforcement efforts. Obviously, any given illegal transaction is more costly, the more aggressively the government pursues the evaders, but there are also inherent costs of shifting economic activity underground. For example, a firm would have difficulties advertising its services and offering warranties.

In addition, the firm is subject to taxation by the mafia. The mafia can tax both above ground and underground transactions, but we assume that its ability to tax legitimate economic activity is limited by the exogenous tax rate $\beta$. The literature often assumes that the mafia can tax only underground output (Grossman, 1995; Johnson et al, 1998). Our assumption is more general and is consistent with anecdotal evidence on Russia and elsewhere (e.g., Goldman, 1995; Schelling, 1984). At the same time, we preserve a constraint on mafia's above ground tax because the firm that operates at least in part legitimately can, in principle, ask the state for protection. This request may be costly to the firm, however, as the mafia may retaliate and state protection may not be reliable. So, we assume that as long as the mafia tax is relatively low, the firm would tolerate it. The mafia may also restrain itself, knowing that setting its tax rate above $\beta$ would push the firm to seek state protection. At first we will assume that the mafia's above ground tax rate is equal to $\beta$. Later we will show that if $\beta$ is the upper limit of the mafia's above ground tax rate and if it is not too large, the mafia will always choose

\footnotetext{
${ }^{4}$ The assumption $C_{\theta \theta \theta} \geq 0$ will be a convenient sufficient condition to ensure that the second order conditions of the mafia's and the government's maximization problems are fulfilled.
} 
to set the tax at $\beta$. Let $m$ represent the mafia's tax on underground sales. The mafia's tax revenue, therefore, is given by

$$
M=m \cdot(1-\theta)+\beta \theta
$$

where $\beta \in[0,1]$.

Under these assumptions, the firm's payoff (profit) is

$$
\Pi=\theta \cdot(1-t-\beta)+(1-\theta) \cdot(1-m)-C(\theta) .
$$

We assume that if the firm's profit either above or below ground becomes negative, the firm goes out of business, in which case all players receive a payoff of zero. When the firm's profit is exactly zero (so it is indifferent between producing and not producing) we assume the firm stays in business. The state's payoff is its tax revenue,

$$
G=t \cdot \theta
$$

The timing of this complete information game is as follows:

Step 1: The state and mafia simultaneously choose their respective tax rates $t$ and $m$. Step 2: The firm chooses $\theta$, if there exists non-negative $\theta$ such that the firm's profit is non-negative. Otherwise, the firm does not produce.

One might argue that it is more difficult for the state to adjust its tax rate than it is for the Mafia. If this is true, then it would be more reasonable to have the state choose its tax rate first and for the mafia to follow. We believe, however, that while it is indeed difficult for a democratic state to change statutory tax rates, the degree of enforcement of the existing tax legislation can be varied rather easily. For this reason, we decided to let both tax rates to be chosen simultaneously. Letting the government move first simply reinforces the main results of the model (Osborne, 1999). 


\subsection{Taxation and Evasion in the Absence of the Mafia}

Because the focus of this paper is to examine the effect of the mafia's presence on optimal tax policy of the state, it is useful to begin the analysis by considering a benchmark case without the mafia. Let $m=\beta \equiv 0$ in the above model. We therefore solve a two-stage game in which the government chooses the tax before the firm makes its evasion decision. Then the firm's profit is given by

$$
\Pi_{-m}=\theta \cdot(1-t)+(1-\theta)-C(\theta)=1-\theta \cdot t-C(\theta) .
$$

The subscript $-m$ indicates the absence of the mafia. The first-order condition for this case is

$$
C_{\theta}(\theta)=-t
$$

which defines the optimal $\theta$ as a function of $t$. The second order condition is clearly satisfied, given the properties of $C(\theta)$. Assuming an interior solution, the Implicit

Function Theorem implies

$$
\partial \theta / \partial t=-1 / C_{\theta \theta}<0 \text { and } \partial^{2} \theta / \partial t^{2}=\left(C_{\theta \theta}\right)^{-2} \cdot C_{\theta \theta \theta} \cdot \partial \theta / \partial t \leq 0
$$

where we omitted the argument of the cost function for notational simplicity. The first order conditions for government's problem (3) are

$$
\theta+t \cdot \partial \theta / \partial t=0 \text { or } t=\theta \cdot C_{\theta \theta}(\theta)
$$

The second order condition for government's problem is satisfied, given (6). Note that (7) defines the optimal tax rate implicitly, because, according to (5), optimal $\theta$ is a function of $t$. Note also, that (7) defines $t^{*}$ only if its solution is less than or equal to 1 . If the solution to (7) is greater than 1 , then $t^{*}=1$ and $\theta^{*}$ can be found from $C_{\theta}=-1$. (We use 
superscript ${ }^{\prime} *$ ' to denote equilibrium values of the model's variables as functions of the model's parameters only.)

Assuming, however, that $t^{*}<1$ and combining (5) and (7), the equilibrium value of $\theta$ is defined by

$$
C_{\theta}\left(\theta^{*}\right)=-\theta^{*} \cdot C_{\theta \theta}\left(\theta^{*}\right)
$$

Notice that given the properties of $C(\theta),(8)$ has an interior solution as long as

$\left|C_{\theta}(1)\right|<C_{\theta \theta}(1)$. From (5), the firm's profit in equilibrium is

$$
\Pi_{-m}^{*}=1+\theta^{*} \cdot C_{\theta}\left(\theta^{*}\right)-C\left(\theta^{*}\right),
$$

where $\theta^{*}$ is defined via (8). Government revenue is given by

$$
G_{-m}^{*}=-\theta^{*} \cdot C_{\theta}\left(\theta^{*}\right)
$$

If $\left|C_{\theta}(1)\right| \geq C_{\theta \theta}(1)$, in equilibrium the firm would refrain from underground activities, setting $\theta$ to 1 . The optimal tax rate in this case is $t=-C_{\theta}(1)$. This is because, for any $t$ greater than that, the firm's best response would be to shift to an interior solution and given $\left|C_{\theta}(1)\right| \geq C_{\theta \theta}(1), \partial G_{-m} / \partial t \leq 0$ at $t \geq-C_{\theta}(1)$.

The above results can be summarized in the following Proposition.

Proposition 1. In the game without the mafia,

(1) a subgame perfect Nash equilibrium in pure strategies always exists and is unique;

(2) if $\left|C_{\theta}(1)\right| \geq 1$, equilibrium $t^{*}$ and $\theta^{*}$ are both equal to 1 .

Assume that $C_{\theta}(1)>-1$. Then, 
(3) if $\left|C_{\theta}(1)\right|<C_{\theta \theta}(1)$ and if $t^{*}$ implied by (7) is less than 1 , the game has an interior solution (i.e., $0<\theta^{*}<1$ ) defined by (8). The firm's profit and government revenue then are given by (9) and (10), respectively.

(4) if $\left|C_{\theta}(1)\right|<C_{\theta \theta}$ (1) and if the solution to (7) is greater than or equal to 1 , then $t^{*}=1$ and $\theta^{*}>0$ is defined by $C_{\theta}\left(\theta^{*}\right)=-1$;

(5) if $\left|C_{\theta}(1)\right| \geq C_{\theta \theta}(1)$, then $\theta^{*}=1$ and $t^{*}=-C_{\theta}(1)$.

The formal proof is presented in the Appendix.

\subsection{Taxation and Evasion in the Presence of the Mafia}

Let us now turn to the analysis of the game with the mafia. The first order condition for the firm's problem (2) is

$$
C_{\theta}(\theta)=m-(t+\beta)
$$

As in the game without the mafia, the second order condition can be readily verified. Also, as before, the comparative statics of $\theta$ with respect to $t$ are given by (6). In addition,

$$
\partial \theta / \partial m=1 / C_{\theta \theta}>0 \text { and } \partial^{2} \theta / \partial m^{2}=-\left(C_{\theta \theta}\right)^{-2} \cdot C_{\theta \theta \theta} \cdot \partial \theta / \partial m \leq 0 .
$$

Equation (11) determines the firm's behavior given that $\Pi \geq 0$ and the tax burden on above ground output is less than or equal to $100 \%$. Notice that the tax rate on the firm's legal sales is equal to $t+\beta$ (recall that we are assuming for the time being that the mafia sets its tax rate on above ground output at $\beta$ ). If this rate is greater than 1 , the firm would choose not to produce any output above ground (but it will not necessarily shift it underground). This situation clearly cannot represent a subgame perfect equilibrium in 
pure strategies and we can limit our attention to the case when $t+\beta \leq 1$. Let us first assume that $t+\beta<1$ (i.e., we have an interior solution for above ground tax rates). In this case, the first order condition for the government problem, as in (7), results in

$$
t=\theta \cdot C_{\theta \theta}
$$

The second order condition is satisfied iff $C_{\theta \theta \theta} / C_{\theta \theta}<2 / \theta$.

From (1) and (12), the first order condition for the mafia implies that

$$
m=\beta+(1-\theta) \cdot C_{\theta \theta}
$$

The second order condition

$$
(1-\theta) \cdot C_{\theta \theta \theta} / C_{\theta \theta}-2<0
$$

holds, as long as $C_{\theta \theta \theta}$ is not too large relative to $C_{\theta \theta}$. From (13) and (14), and assuming interior equilibrium, $\theta^{*}$ is implicitly defined via

$$
C_{\theta}\left(\theta^{*}\right)=\left(1-2 \theta^{*}\right) \cdot C_{\theta \theta}\left(\theta^{*}\right)
$$

Similarly to (8), this equation defines an interior $\theta^{*}$ (in fact, $\theta^{*}$ between $1 / 2$ and 1 ) iff $-C_{\theta}(1)<C_{\theta \theta}$ (1). If this inequality does not hold, the equilibrium $\theta^{*}=1$ and similarly to the model without the mafia, one of the possible equilibrium government tax rates is determined from $t^{*}=-C_{\theta}(1)$. The equilibrium tax rate on underground output then is $m^{*}=\beta .^{5}$

\footnotetext{
${ }^{5}$ To see this, note that the firm's best response to given $t, \beta$, and $m$ is determined by the derivative of its profit function $\partial \Pi / \partial \theta=-(t+\beta-m)-C_{\theta}$. If this derivative is nonnegative at $\theta=1$, then it will be positive for all $\theta<1$, and best response to $t, \beta, m$ is $\theta=1$. Assuming that $m=\beta, \partial \Pi / \partial \theta \geq 0$ for all $t \leq-C_{\theta}(1)$. Also, if $m=\beta$ and $-C_{\theta}(1) \geq C_{\theta \theta}(1), \partial G / \partial t<0$ for all $t \geq-C_{\theta}(1)$. Therefore, $t^{*}=-C_{\theta}(1)$ and $\theta^{*}=1$. Obviously, the mafia's best response to these $t^{*}$ and $\theta^{*}$ is any feasible $m$, but only $m^{*}=\beta$ would constitute Nash equilibrium. Unlike in the game without the mafia, however, the game with the mafia can have multiple subgame perfect equilibria corresponding to $\theta^{*}=1$, because increasing $m^{*}$ beyond
} 
Note that $\theta^{*}$ is independent of $\beta$. Combined with (14), this implies that in the interior equilibrium, mafia's optimal tax rate increases in $\beta$. We obtained this assuming that the mafia sets its tax rate at $\beta$. This proves that in the interior solution, the mafia will indeed set its above ground tax rate at its upper limit $\beta$.

So far, we have assumed that $t+\beta<1$. It is quite possible, however, that $t$ defined in (13) would exceed (1- $\beta$ ). Then, if the mafia sets its above ground tax rate at $\beta$, the combined tax burden on the firm's above ground output would be greater than $100 \%$. We assume that in this case the firm would cease legal production and, therefore, this situation cannot constitute an equilibrium. On the other hand, we assume that if the combined tax burden above ground is equal to $100 \%$, the firm would determine its optimal underground output $(1-\theta)$ and would produce $\theta$ above ground, even though its profit from legal production would be zero. Clearly, if (13) results in $t>1-\beta$, both the state and mafia would be interested in raising their tax rates, provided that $t+b=1$, where $b \in[0, \beta]$ is now the mafia's rate. In other words, the government and mafia would engage in a "divide-the-dollar" game with respect to the above ground revenue, splitting it between themselves, and the number of possible equilibria would be infinite. When this is the case, the firm's payoff becomes

$$
\Pi=(1-\theta) \cdot(1-m)-C(\theta) .
$$

The first order condition for its maximization is

$$
-(1-m)-C_{\theta}=0 .
$$

$\beta$ would not change mafia's payoff but would allow government to raise its tax rate to above $-C_{\theta}(1)$, without pushing the firm underground. 
The second order condition is clearly satisfied, because $C_{\theta \theta}>0$ by assumption. From this we again obtain

$$
\partial \theta / \partial m=1 / C_{\theta \theta}
$$

The mafia's payoff is

$$
m \cdot(1-\theta)+b \cdot \theta
$$

with the first order condition

$$
1-\theta-(m-b) \cdot \partial \theta / \partial m=0
$$

The second order condition is satisfied, as long as $C_{\theta \theta \theta} / C_{\theta \theta}<2$. Combining (17), (18), and (20), the equilibrium $\theta^{*}$ is determined from

$$
C_{\theta}\left(\theta^{*}\right)=\left(1-\theta^{*}\right) \cdot C_{\theta \theta}\left(\theta^{*}\right)-(1-b)
$$

The above results can be summarized in the following Proposition.

Proposition 2. Assume that $C_{\theta \theta \theta} \leq 2 \cdot C_{\theta \theta}$. Then,

(1) a pure strategy subgame perfect Nash equilibrium of the game with the mafia exists;

(2) if (13) defines $t \leq 1-\beta$ and if $-C_{\theta}(1)<C_{\theta \theta}$ (1), this equilibrium is unique and the equilibrium values of $\theta, t$, and $m$ are determined via, respectively, (15), (13), and (14); $\theta^{*}$ and $t^{*}$ are independent of $\beta$;

(3) if (13) defines $t \leq 1-\beta$ and if $-C_{\theta}(1) \geq C_{\theta \theta}$ (1), the game with the mafia has multiple subgame perfect equilibria with $\theta^{*}=1, m^{*} \geq \beta$, and $t^{*}=-C_{\theta}(1)+\beta-m^{*}$;

(4) when the solution to (13) is greater than $1-\beta$, the game with the mafia has multiple 
equilibria with $\theta^{*}$ determined by (21), mafia's above and below ground tax rates given, respectively, by $b \in[0, \beta]$ and $m^{*}=1+C_{\theta}\left(\theta^{*}\right)$, and government tax rate $t^{*}=1-b$.

We will discuss the interior equilibrium of this game shortly. Notice, however, that the existence of the corner solutions (the "divide-the-dollar" equilibria) also has important policy implications. If the upper limit on the mafia's above ground tax rate is relatively large (i.e. if the mafia is "strong") so that in equilibrium the government and mafia appropriate all of the firm's above ground profits, any reduction of government tax rates (provided that $t$ remains greater than $1-\beta$ ) would only give the mafia a greater share of revenues. If this is the case in Russia, then the currently popular calls for lowering the tax burden on Russia's enterprises may be misguided, unless such reductions are accompanied by serious efforts to reduce the ability of organized crime groups to tax legitimate enterprises.

\subsection{Comparison of Results}

Let us return to the case of unique equilibrium with $t^{*}+\beta<1$ and compare the values of $\theta^{*}$ and $t^{*}$ in games with and without the mafia. Recall first that in the game without the mafia, $\theta^{*}$ was determined by (8). In the presence of the mafia, $\theta^{*}$ is obtained from (15), as long as the conditions in part (2) of Proposition 2 hold. It is instructive to compare these solutions. Given (8) and recalling that $C_{\theta \theta}>0$, we have

$C_{\theta}\left(\theta_{-m}^{*}\right)<-\theta_{-m}^{*} \cdot C_{\theta \theta}\left(\theta_{-m}^{*}\right)+\left(1-\theta_{-m}^{*}\right) \cdot C_{\theta \theta}\left(\theta_{-m}^{*}\right)=\left(1-2 \theta_{-m}^{*}\right) \cdot C_{\theta \theta}\left(\theta_{-m}^{*}\right)$. 
Notice that the right hand side of (22) declines in $\theta$, as long as $C_{\theta \theta \theta} / C_{\theta \theta}<2$, while the left hand side of (22) increases in $\theta$. Therefore, in order for (15) to hold, it must be that

$$
\theta_{-m}^{*}<\theta^{*}
$$

Since $C_{\theta \theta \theta} \geq 0$, this in turn implies that

$$
t^{*}=\theta^{*} \cdot C_{\theta \theta}>\theta_{-m}^{*} \cdot C_{\theta \theta}\left(\theta_{-m}^{*}\right)=t_{-m}^{*} .
$$

Furthermore, government revenues in equilibrium have the same relationship

$$
G^{*}=\theta^{*} \cdot t^{*}>\theta_{-m}^{*} \cdot t_{-m}^{*}=G_{-m}^{*}
$$

By comparing $\Pi^{*}$ and $\Pi_{-m}^{*}$, and using (23) and the properties of $C(\theta)$, we can also demonstrate in a straightforward fashion that the firm is worse off in the presence of the mafia than without it. Therefore, we have,

Proposition 3. When $C_{\theta \theta \theta} \leq 2 \cdot C_{\theta \theta}$ and (13) defines $t \leq 1-\beta$, the following relationships exist between the solutions of the games with the mafia and without the mafia:

$$
\begin{array}{ll}
\theta_{-m}^{*}<\theta^{*} ; & t_{-m}^{*}<t^{*} \\
G_{-m}^{*}<G^{*} ; & \Pi_{-m}^{*}>\Pi^{*} .
\end{array}
$$

Proposition 3 represents one of the important results of the paper. Intuitively, for any given above ground tax rate, the mafia's taxation of underground sales makes it less attractive for the firm to go underground. In addition to the government tax rate $t$, the firm's allocation of output between legal and illegal sectors in the game with the mafia depends on the difference between mafia's tax rates, $m-\beta$. As long as the mafia's above ground tax rate cannot be too large (i.e. $\beta$ is relatively small), the mafia chooses to 
charge a higher tax underground than it charges above ground $(m>\beta)$. Therefore, for any given $t$, the mafia's presence induces the firm to sell a greater proportion of output above ground. This allows the government to increase its tax rate relative to the case without the mafia, without pushing the firm too far underground. (If $\beta$ is large, some of the equilibria may consist of lower $t^{*}$ and $G^{*}$ than in the absence of the mafia.) Interestingly, (23) also implies that the presence of the mafia reduces the waste of resources associated with transacting underground.

We do not want to take these results too far, because our model does not take into account some relevant features of reality such as the welfare objective of a democratically elected government and the provision of public goods by both the government and the mafia. Nonetheless, to the extent that revenue maximization serves as one of the government's important goals and in the economies where taxes provide little in terms of public goods, the finding is important. In particular, Proposition 3 may provide at least a partial explanation for the relatively high effective tax rates in Russia, where organized crime apparently routinely extorts protection payments from firms and where the assumption that the government maximizes revenue may not be far fetched.

\subsection{Comparative Statics}

It is instructive to consider comparative statics with respect to $\beta$. Differentiating (13) and keeping in mind that $\partial \theta^{*} / \partial \beta=0$, we can easily establish that $\partial t^{*} / \partial \beta=0$ and, therefore, $\partial G^{*} / \partial \beta=0$. Also, from (14) and (15) $\partial m^{*} / \partial \beta=1$ and then from (1), 
$\partial M^{*} / \partial \beta=1$. Finally, given the above comparative statics and the firm's payoff specified in (2), $\partial \Pi^{*} / \partial \beta=-1$.

The comparative statics with respect to $\beta$ can be explained by the aforementioned fact that as long as $\beta$ is sufficiently small (i.e., $t+\beta<1$ ), the firm is concerned only with the difference between the mafia's underground and above ground rates. Meanwhile, it is optimal for the mafia to keep this difference at $(1-\theta) \cdot C_{\theta \theta}$. Since in equilibrium, the latter expression is independent of $\beta$, this implies that the government's tax rate and revenue would also be independent of $\beta$. If $\beta$ is relatively large, however, the interests of government and the mafia begin to collide.

Earlier, we established that the presence of the mafia may be beneficial to the revenue-maximizing government, because the mafia makes it less attractive for the firm to escape government taxation by going underground. Additionally, the above comparative statics results suggest that the increase of the mafia's ability to tax above ground transactions is, up to a point, of little concern to the government, implying that it may not be interested in fighting the mafia. Notice, however, that the government has an incentive to prevent the mafia from raising its tax on above ground output too much.

In the remainder of this section we analyze how a change in the cost of shifting sales underground affects $\theta^{*}$. Let us begin with a simple example that also illustrates nicely the other results of our analysis. Assume

$$
C(\theta)=k \cdot(1-\theta)^{2}
$$

where $k>0$ is a parameter. In this case, the first order condition for the firm results in

$$
\theta=1-(t+\beta-m) / 2 k
$$


The best response functions of the government and the mafia are, respectively,

$$
\begin{aligned}
& t=k-(\beta-m) / 2 \\
& m=\beta+t / 2 .
\end{aligned}
$$

These best response functions imply the following interior equilibrium solutions.

$$
\begin{aligned}
& \theta^{*}=2 / 3 \\
& t^{*}=(4 / 3) \cdot k \\
& m^{*}=\beta+(2 / 3) \cdot k .
\end{aligned}
$$

Note that $\theta^{*}$ is not only independent of $\beta$, but also of $k$. The requirement that the above ground tax burden is less than one implies that

$$
(4 / 3) \cdot k \leq(1-\beta) \text {. }
$$

The revenues of the government and mafia are, respectively,

$$
\begin{aligned}
& G^{*}=t \cdot \theta=(8 / 9) \cdot k \\
& M^{*}=\beta \cdot \theta+m \cdot \theta=\beta+(2 / 9) \cdot k
\end{aligned}
$$

It is also easy to show that when $(4 / 3) \cdot k>(1-\beta)$, the government and the mafia completely tax away the above ground revenue of the firm. Any pair of tax rates, such that $t^{*}+b=1$ and $0 \leq b \leq \beta$, would be possible in equilibrium. In other words, the government and mafia would engage in "divide-the-dollar" game with respect to the above ground revenue, splitting it between themselves, and the number of possible equilibria would be infinite. In this case, $\theta^{*}=1-(1-b) / 4 k$, and the tax agencies' revenues and the firm's profits are

$$
G^{*}=(1-b) \cdot[1-(1-b) / 4 k]
$$




$$
\begin{aligned}
& M^{*}=(1-b)^{2} / 8 k \\
& \Pi^{*}=(1-b)^{2} /(16 k) \geq 0 .
\end{aligned}
$$

Notice that this example has interesting comparative statics with respect to $k$, for the case of $t+\beta<1$. For example, $\partial \theta^{*} / \partial k=0, \partial t^{*} / \partial k>0$, and $\partial m^{*} / \partial k>0$. Unfortunately, for these results to hold in a more general setup, where costs are given by $C(\theta, k), C_{k}>0$, we would need to impose ad hoc constraints on second and third cross partials of the cost function. Complications arise because the effects of the increase in $k$ have contradictory effects on different players. Consider, for example, the relationship between $\theta^{*}$ and $k$. On the one hand, higher costs engendered by higher $k$ make it more difficult for the firm to evade the government's tax by going underground. On the other hand, greater $k$ may induce the government to raise its tax rate, pushing the firm underground. The combined effect on $\theta$ is in general uncertain. However, the fact that the overall consequences of an upward shift of underground operating costs are generally unpredictable may be interesting in itself.

\section{An Extension of the Basic Model}

Our basic model can be extended in a number of useful ways. Here we will use numerical methods to describe the effect of replacing the inelastic demand for the firm's output with a linear demand curve. We will assume that $C(\theta)=k \cdot(1-\theta)^{2}$. 
Let the demand curve facing a monopolistic firm be $Q=A-s \cdot p$, where $Q$ and $p$ are, respectively, output and per unit price, and $A$ and $s$ are exogenous parameters. The firm's problem then can be described as

$$
\begin{aligned}
& \max _{\theta, p} \Pi=\left(\theta(p-t-\beta)+(1-\theta) \cdot(p-m)-k(1-\theta)^{2}\right) \cdot(A-s \cdot p) \\
& \text { s.t. } \theta \in[0,1]
\end{aligned}
$$

From the first order conditions for (26), and assuming an interior solution, we obtain

$$
\begin{aligned}
& \theta=1-\frac{t+\beta-m}{2 k} \\
& p=\frac{A}{2 s}+\frac{t+\beta}{2}-\frac{(t+\beta-m)^{2}}{8 k}
\end{aligned}
$$

The government's revenue function becomes:

$$
G=t \cdot(A-s \cdot p) \cdot \theta
$$

In the benchmark case without the mafia (i.e., $m \equiv 0$ and $\beta=0$ ), we can substitute in the values of $p$ and $\theta$ from (27) and (28) into (29) and obtain

$$
G_{-m}=\frac{t(2 k-t)}{14 k^{2}}\left(4 A k-4 s t k+s t^{2}\right)
$$

The government optimizes over $t$, resulting in the following first order condition (the subscript $-m$ has been omitted):

$$
\frac{\partial G}{\partial t}=t^{3}-\frac{9}{2} k t^{2}+\frac{2 k}{s}(A+2 s k) t-\frac{2 A k^{2}}{s}=0
$$

The analytic solution for $t_{-m}^{*}$ is obviously cumbersome and we omit it here. Our simulations indicate that the optimal tax is always lower than $k$ (recall that in the basic model, $t_{-m}^{*}=k$ ) although for low $k$ the difference is very small. The value of $\theta^{*} \in[0,1]$, 
on the other hand, is greater for the model with linear demand, although again, for low $k$ the difference is negligible.

When the mafia is included, the first order conditions for the government are again cubic in $t$. The mafia's revenue is

$$
M=(A-s \cdot p) \cdot(\beta \theta+(1-\theta) \cdot m)
$$

The first order conditions for $m$ are also cubic in $m$, so solving for a subgame perfect Nash equilibrium analytically becomes problematic. Moreover, the resulting expressions for $t$ and $m$ would be difficult to analyze. Instead, we constructed the mafia's best response function to $t$ numerically (i.e. found the $m(t)$ that maximized the mafia's revenues for given values of $t$ ). We then substituted these $m(t)$ values into the first order condition for the government and found the value of $t$ that (approximately) solved the first order condition for the given values of $k$ and $\beta$. The resulting estimate of $t^{*}$ was used to estimate the mafia's optimal tax rate $m^{*}=m\left(t^{*}\right)$. Given the estimates of $t^{*}$ and $m^{*}$ we could then calculate the firm's choice of $p^{*}$ and $\theta^{*}$, as well as the firm's profit, government's revenue, and mafia's revenue. During these simulations we always made sure that the second order conditions were satisfied.

Setting $A=10, s=1$, and $k=0.1$, we found that in the absence of the mafia, the government chooses $t_{-m}^{*}$ of about 0.1 (recall that for relatively low values of $k$, the solution for $t^{*}$ is approximately equal to $k$ when the mafia is absent). The other equilibrium values were as follows: $p_{-m}^{*}=5.037, Q_{-m}^{*}=4.963, \theta_{-m}^{*}=0.5, G_{-m}^{*}=0.248$, $\Pi_{-m}^{*}=24.63$. 
With the mafia present and $\beta=0.2$, the government sets $t^{*}$ to approximately 0.132. The remaining equilibrium values are: $p^{*}=5.16, Q^{*}=4.84, \theta^{*}=0.665, m^{*}=$ $0.265, G^{*}=0.425, M^{*}=1.073$, and $\Pi^{*}=23.422$. Not surprisingly the introduction of the mafia leads to a higher output price and lower output volume. Nonetheless, the government's tax rate and revenue increase due to the mafia's presence, while the share of above ground sales also rises, i.e. qualitatively the same results as in Proposition 3. Note, however, that the mafia's presence may have an opposite effect on government revenues if demand is sufficiently elastic. (For example, if $s=10$, resulting in demand elasticity in equilibrium in excess of -2 .)

We have repeated the simulations for various values of $\beta$. The tables below summarize the resulting approximations of comparative statics with respect to $\beta$ and compare them with comparative statics for the basic model. (In all simulations, $A=10$, $s=1$.) Table 1 presents these comparative statics, where $\beta$ increases from 0.2 to 0.3 (with $k=0.1$ ). 
Table 1. An example of comparative statics with respect to $\beta$ for the model with linear demand curves.

\begin{tabular}{|c|c|c|c|}
\hline Results with inelastic demand & $\beta=0.2$ & $\beta=0.3$ & Same result? \\
\hline$\partial t^{*} / \partial \beta=0$ & 0.132 & 0.132 & yes \\
\hline$\partial m^{*} / \partial \beta>0$ & 0.265 & 0.365 & yes \\
\hline$\partial \theta^{*} / \partial \beta=0$ & 0.665 & 0.665 & yes \\
\hline$\partial \Pi^{*} / \partial \beta<0$ & 23.422 & 22.94 & yes \\
\hline$\partial G^{*} / \partial \beta=0$ & 0.425 & 0.42 & no \\
\hline$\partial M^{*} / \partial \beta>0$ & 1.073 & 10.27 & yes \\
\hline
\end{tabular}

In addition, the increase in $\beta$ causes the price of output to rise and the volume to fall. Notice that most of the results for the model with inelastic demand hold for this linear demand curve case. The only exception is that government revenue decreases instead of being unchanged as the mafia gets stronger. This is because as in the inelastic demand model, an increase in $\beta$ leads to a higher mafia tax both above and below ground. Meanwhile, neither optimal government tax rate nor $\theta^{*}$ are affected by $\beta$. Unlike in the basic model, however, higher mafia tax leads to lower output and, therefore, lower government revenue. This is an important difference. It suggests that when the demand for the firm's good is elastic, even the revenue-maximizing government has incentives to fight the ability of the mafia to tax the above ground output of firms.

Another rather straightforward extension of our model would be to assume that the government is interested in enhancing social welfare as well as in maximizing revenues. To reflect this we can assume that the government's payoff is a weighted sum of its tax revenues and the (negative of) costs of operating underground, i.e. 


$$
G=\alpha \cdot t \cdot \theta-(1-\alpha) \cdot C(\theta)
$$

This extension does not change the main results of the model. Specifically, while the optimal values of the model's variables change, the relationship between these equilibrium values in the models with and without the mafia remains exactly the same. Also, optimal $\theta$ remains independent of the value of $\beta$ as long as beta is sufficiently low.

\section{Conclusions}

We examined optimal taxation of a tax-evading firm by a revenue-maximizing government with and without the mafia. One of the important results of our analysis is that the presence of the mafia (as long as the mafia is not too "strong") makes it relatively more costly for the firm to shift its activities underground and, therefore, reduces tax evasion and increases the government's tax rate and revenues. Therefore, governments may find the presence of the mafia useful in combating tax evasion. This consideration may in part explain the relatively timid efforts of some governments in the countries with weak tax administrations (such as, for example, many former Soviet republics) to fight organized crime. It also partly explains the relatively high effective tax burdens in some of these countries.

The above results were obtained in a relatively general setup for the case of inelastic demand. The presence of the mafia may also benefit the revenue-maximizing government if the firm faces linear demand curves (at least for some parameter values), but the presence of the mafia in this case leads to lower output and higher price. Therefore, when demand is elastic, a government that is interested in overall welfare would have incentives to reduce the mafia's role. 
While the benefit to the revenue-maximizing government from the mafia's presence underground is relatively easy to understand, the mafia's ability to tax above ground output might be expected to hamper the government's revenue raising potential. It turns out that this is not always the case. If we define the mafia's strength as its ability to tax the firm's above ground output, then in the model with inelastic demand, the government's ability to collect revenue from the firm does not change (at least up to a point) as the mafia becomes stronger. This implies that when demand is inelastic, revenue-maximizing government would not be interested in fighting the mafia's ability to tax above ground output. Notice, however, that this result does not hold when demand is elastic.

We also found that the increase in operating costs of shifting sales underground has a generally unpredictable effect on the optimal tax rates and tax collections. The outcome here depends on the specifics of the change in the cost function. This result suggests that either the government's efforts to raise the costs of underground operations or the mafia's efforts to lower them may not necessarily produce the intended outcomes.

\section{References}

Berkowitz, Daniel and Wei Li, 1999, "Tax Rights in Transition Economies: A Tragedy of the Commons?" Journal of Public Economics, forthcoming.

Cowell, Frank and James Gordon, 1995, "Auditing with Ghosts," in Fiorentini, Gianluca and Sam Pelzman, eds., The Economics of Organised Crime, Cambridge, MA: Cambridge University Press, pp. 185-96.

Egorova, E.N. and U.A. Petrov, 1996, "Otsenka Polnoj Stavki Nalogooblozhenia Dobavlennoj Stoimosti v Rossii i Zarubezhnyh Stranah," Ekonomika $i$ Matematicheskie Metody, 32, 2:38 - 48. 
Gambetta, Diego, 1993, The Sicilian Mafia: The Business of Private Protection, Cambridge, MA: Harvard University Press.

Goldman, Marshall, 1996, "Why is the Mafia So Dominant in Russia?" Challenge, 39, 1:39-47, January - February.

Grossman, Herschel, 1995, "Rival Kleptocrats: The Mafia vs. the State," in Fiorentini, Gianluca and Sam Pelzman, eds., The Economics of Organised Crime, Cambridge, MA: Cambridge University Press, pp. 143-60.

Johnson, Simon, Daniel Kaufmann, and Pablo Zoido-Lobaton, 1998, "Regulatory Discretion and the Unofficial Economy, AER Papers and Proceedings, 88, 2:38792, May.

Keen, Michael, 1998, "Vertical Tax Externalities in the Theory of Fiscal Federalism," IMF Staff Papers, 45, 3:454-85, September. and Christos Kotsogiannis, 1996, "Federalism and Tax Competition,” mimeo.

Osborne, Stefan, 1999, "Taxation and Evasion in the Presence of Extortion by Organized Crime," Ph.D. Dissertation, Department of Economics, Indiana University, Bloomington, IN.

Reuter, Peter, 1983, Disorganized Crime: The Economics of the Visible Hand, Cambridge, MA: MIT Press.

Schelling, Thomas, 1984a, "What is the Business of Organized Crime?" in Schelling, Thomas, Choice and Consequence, Cambridge, MA: Harvard University Press, pp. 179-94. , 1984b, "Economics and Criminal Enterprise," in Schelling, Thomas, Choice and Consequence, Cambridge, MA: Harvard University Press, pp. 158-78.

World Economic Forum, 1997, Executive Survey, Global Competitiveness Report, Geneva, Switzerland: World Economic Forum.

Zhuravskaya, Ekaterina and Timothy Frye, 1998, "The Rise of the Racket in Russia," mimeo. 


\section{Appendix}

Proof of Proposition 1. (Note: we are not using “ $-m$ " subscript anywhere in this proof because all variables in the proof relate to the game without the mafia.) It is useful first to describe the best response (BR) function of the firm, $\theta(t)$. Clearly, $\theta(0)=1$.

Next, observe that given $t$, the derivative of the firm's profit function is

$$
\partial \Pi / \partial \theta=-t-C_{\theta}
$$

Notice that $\partial \Pi / \partial \theta \geq 0$ as long as $-C_{\theta}(\theta) \geq t$. Therefore, by continuity of $C_{\theta}(\theta)$, if $-1<C_{\theta}(1)<0$, there exists $t_{L}=-C_{\theta}(1)>0$ such that $\partial \Pi / \partial \theta>0$ for all $t<t_{L}$ and $\theta \leq 1, \partial \Pi / \partial \theta=0$ for $t=t_{L}$ and $\theta=1$, and $\partial \Pi / \partial \theta<0$ for $t \geq t_{L}$ and $\theta=1$. Hence, $\theta(t)=1$ for all $t \leq t_{L}$, and $\theta(t)<1$ for all $t>t_{L}$. If $\left|C_{\theta}(1)\right| \geq 1$, then $\partial \Pi / \partial \theta \geq 0$ for all feasible $\theta$ and $t$ and, therefore, $\theta(t)$ is always 1. (This proves part (2) of the Proposition.) In the rest of the proof we will assume that $\left|C_{\theta}(1)\right|<1$.

If $\left|C_{\theta}(0)\right|<1$, then there exists $t_{H}<1$ such that $\partial \Pi / \partial \theta \leq 0$ for all $t \geq t_{H}$ and $\theta \geq 0, \partial \Pi / \partial \theta=0$ for $t=t_{H}$ and $\theta=0$, and $\partial \Pi / \partial \theta>0$ for $t<t_{H}$ and $\theta=0$, i.e. $\theta=0$ for all $t>t_{H}$. Define $S=\left[-C_{\theta}(1), \min \left\{1,-C_{\theta}(0)\right\}\right]$. Clearly, $S \subseteq[0,1]$ is non-empty and compact. Observe that for all $t \in S, \theta(t)$ is implicitly defined by $C_{\theta}=-t$ and $\partial^{2} \theta / \partial t^{2} \leq 0$. Therefore $\theta(t)$ is weakly concave on $S$.

Given that $C_{\theta}(\theta)$ is continuous, it is straightforward albeit somewhat tedious to demonstrate that $\theta(t)$ is continuous for all $t$. This completes the description of the firm's BR function. Now, we will prove the specific parts of the proposition. 
(1) Given the sequential nature of the game, subgame perfect Nash equilibrium is achieved when

$G(t)=t \cdot \theta(t)$ is maximized, where $\theta(t)$ is the firm's BR. $G(t)$ is continuous and is defined on a compact set. Therefore, it reaches its maximum and equilibrium exists. Moreover, this maximum cannot exist on intervals $\left[0, t_{L}\right)$ and $\left(t_{H}, 1\right]$ (if $t_{L}>0$ and $t_{H}<1$ ). This is because $G\left(t_{L}\right)$ is greater than it is at any point from the first interval, and $G\left(t^{\prime}\right)$ is greater than it is at any point from the second interval, where $t^{\prime}<t_{H}$. This means that $G(t)$ reaches its maximum at some point on $S$. The fact that $\theta(t)$ is weakly concave and monotonically decreasing on $S$ implies that $G(t)$ is strictly concave on $S$. Therefore, it has a unique maximum.

(2) This part was proven above.

(3) This part follows from the fact that under the stated assumptions both necessary and sufficient conditions for an interior equilibrium are satisfied.

(4) If $\left|C_{\theta}(1)\right|<C_{\theta \theta}(1)$, then given that $\partial \theta / \partial t<0, \partial G(t) / \partial t>0$ for any feasible $\theta$ and for all $t$ that are less than the solution to (7). Therefore, optimal $t$ is 1 (recall that we assume that the firm's above ground sales are zero if $t>1$ ). Given $t^{*}=1, \theta^{*}$ is defined by $C_{\theta}\left(\theta^{*}\right)=-1$. Such $\theta^{*} \in(0,1)$ clearly exists if $t$ from (7) is greater than 1 , and given our assumption that $\left|C_{\theta}(1)\right|<1$.

(5) Let $\theta=1$ and $t=t_{L}=-C_{\theta}(1)$. Then $\partial G(1) / \partial t=1+C_{\theta}(1) / C_{\theta \theta}(1) \leq 0$. Given the properties of $C(\theta), \partial G(t) / \partial t<0$ for all $t>-C_{\theta}(1)$ or for all $t>t_{L}$. Therefore, $G(t)$ is maximized at $t=t_{L}=-C_{\theta}(1)$. 